\title{
"Viagens na Minha Terra": A Literatura e a Cultura no Fomento do Turismo
}

https://doi.org/10.21814/uminho.ed.48.6

\author{
Adelino Timóteo \\ Escritor freelancer, Moçambique \\ Adelinotimóteo@gmail.com \\ Sara Jona Laisse \\ Escola Superior de Gestão Ciência e Tecnologia, Universidade Politécnica, Maputo, Moçambique \\ https://orcid.org/0000-0001-8877-8340 \\ saralaisse@yahoo.com.br
}

\section{Resumo}

A obra literária é composta por características e códigos que influenciam o leitor. Assim sendo, defendemos que, propondo textos ou obras literárias que sugiram lugares e aspectos culturais sobre Moçambique e colocando-as ao dispor do turista, este poderá sentir-se influenciado a procurar conhecer esses lugares ou culturas, o que poderá consequentemente impulsionar o desenvolvimento económico. Desse modo, aventamos a possibilidade de que a produção literária de um país, em primeira instância, e a produção cultural, em segunda, possam fomentar o turismo. Assim, a nossa análise seguirá uma metodologia exploratória descritiva, num estudo que pretende estimular o turismo, a partir das potencialidades da literatura e da cultura; recorrendo à fundamentação teórica em Horellou-Lafarge e Segré (2003/2010), Jauss (1993), Iser (2001) e Laisse (2015). Serão consideradas as seguintes modalidades de análise: mapeamento de textos que sugiram locais turísticos e representações culturais moçambicanas, que julgamos possam ser utilizados para o estabelecimento de correlações entre aspectos reais e ficcionais ou a mimetização da sociedade, que possam alavancar o turismo cultural, sugerindo locais por visitar. Esta proposta tem fundamento na ideia de que existe uma relação que pode ser estabelecida entre uma obra e o seu leitor, que tem a ver com a função da literatura junto ao público e a função social do escritor. Esperamos com esta pesquisa contribuir com uma proposta de catálogo de obras literárias, bem como de lugares culturais ou históricos, que, aliadas a um levantamento mais exaustivo, possam captar turistas e visitantes para Moçambique. 


\section{Palavras-chave}

influência de texto, turismo cultural, literatura e cultura, Moçambique

Uma das mais antigas formas de viajar assenta especialmente no consumo do turismo cultural. Na actualidade, este tipo de turismo continua a ser o sustentáculo da actividade turística em diversos países e regiões. De facto a cultura, na maioria dos casos, constitui um trunfo importante para o desenvolvimento do turismo e para a captação de turistas e visitantes. Ela é o grande vetor que torna possível conhecer os pormenores de uma cidade, vila, aldeia ou, ainda, de um dado momento histórico. (Marujo, 2015, s.p.)

\section{A Literatura e a Sociedade: Do Desenvolvimento Humano ao Desenvolvimento Económico}

$\mathrm{Na}$ abordagem a este tema, duas acepções deverão ser levadas em conta. A primeira, a de que o texto literário é um objecto de arte, um lugar povoado por símbolos e consequentemente de sugestão. Além disso, tal como o afirma Culler (1997, p. 9), é um lugar de representação, a partir do qual a realidade deve ser, claramente, distinguida da representação, que em seu dizer os símbolos e as representações são uma forma de se apreender a realidade a partir de ideias, podendo ser o mais transparente possível. Eles não são a realidade, mas representam-na.

A segunda, a de que o texto literário, sendo um objecto de arte, é também lúdico e a sua ludicidade, na maior parte das vezes, é o que apreende a atenção do leitor. É no âmbito desse aspecto relevante da leitura que pretendemos propor textos que possam, depois de lidos, captar a atenção de leitores, sugerindo-lhes o conhecimento de lugares e culturas moçambicanas. Será assim que, em nosso entender, se pode fomentar o turismo cultural através da literatura.

Fomentar o turismo cultural a partir da literatura consistirá em colocar, ao dispor dos turistas (prováveis leitores), obras literárias que sugiram culturas e lugares de Moçambique para visitar. A base para acreditarmos que isso seja possível fundamenta-se no quadro teórico da receção do texto literário e na influência que o texto literário pode provocar no leitor. Estes aspetos foram estudados por Horellou-Lafarge e Segré (2003/2010), Jauss (1993) e Iser (2001), que abordam o conceito de horizonte de expectativas, afirmando que a leitura de um texto coloca o seu leitor perante uma expectativa sobre a questão estéctica desse mesmo texto, a finalidade a que a obra se destina e, por fim, sobre os valores sociais que ele veicula. Para o presente texto interessa-nos trabalhar com expectativas sociais que um texto pode provocar no turista-leitor.

Assim, iremos propor a disposição de textos literários, cujo contexto abra campo para a exploração do turismo cultural. A ideia que temos é a de que, lendo esses textos, 
os turistas se sintam estimulados a conhecer os lugares e culturas representados e os visitem; o que impulsionaria o desenvolvimento humano, o desenvolvimento intelectual e o desenvolvimento turístico.

O turismo cultural tem conhecido diferentes definições e descrições. Abaixo encaixado está um quadro-resumo (Tabela 1 ) de algumas delas, na perspectiva de diferentes autores citados por Marujo (2015).

\section{Tabela 1}

Definições de turismo cultural.

Fonte. Marujo, 2015, s. p.

\begin{abstract}
Autores Definição/descrição
Wood Os exemplos de situações nas quais o papel da cultura é contextual, e em que a sua função

(1984) é formar o turista numa situação geral e sem uma perspectiva particular de uma identidade cultural específica.

Smith Abarca o pitoresco ou a cor, os vestígios de uma vida em processo de extinção que

Silberberg

permanece na memória humana com as suas casas antiquadas, os seus telhados artesanais, os seus carros... o seu artesanato e trabalhos manuais alheios a todas as técnicas industriais. Aquelas deslocações realizadas para fora do lugar habitual de residência cuja motivação principal ou parcial é o interesse nos aspectos históricos, científicos ou de estilos de vida oferecidos por uma comunidade, região, grupo ou instituição.
\end{abstract}

Richards

Mclntosch

e Goeldner

(1999)

Prentice

Beni

McKercher e

Cros (2002)

Smith (2003)

Craik

Petroman et

al. (2013)

Marujo et al.

O modo como os turistas - aquelas pessoas que viajam fora dos seus locais de residência consomem a cultura.

Todos os aspectos do turismo através dos quais os viajantes aprendem sobre a história e o património de outros ou sobre os seus actuais estilos de vida e formas de pensar.

Turismo construído, oferecido e consumido, explícita ou implicitamente, como uma apreciação cultural, quer como experiência, quer como um ganho de conhecimento.

A afluência de turistas a núcleos receptores que oferecem como produto essencial o legado histórico do ser humano em distintas épocas, representado a partir do património e do acervo cultural, encontrado nas ruínas, nos monumentos, nos museus e nas obras de arte.

O turismo cultural é definido como uma forma de turismo que se baseia nos bens culturais de um destino e os transforma em produtos que podem ser consumidos por turistas.

O turismo cultural é o envolvimento passivo, activo e interactivo com as culturas e comunidades, através do qual o visitante ganha novas experiências de carácter educativo, criativo e divertido.

Excursões frequentes a outras culturas e lugares para aprender acerca dos seus povos, estilos de vida, património e artes, representantes genuínos dessas culturas e dos seus contextos históricos.

Refere-se às formas de arte (cultura) na área urbana e rural de uma região ou país, e define-se como um movimento de pessoas para as atracções culturais longe do seu local de residência habitual com o objetivo de assimilar informações e experiências culturais.

O turismo cultural caracteriza-se pela motivação do turista em conhecer e vivenciar lugares onde o seu alicerce está baseado na história de uma determinada sociedade. 
A referência a essas definições e descrições servirá, para contextualizar, mais adiante, a escolha de textos literários que permitem dar a conhecer lugares e representações de culturas moçambicanas. $O$ cerne deste estudo é a informação que esses textos podem dar e não a conceptualização do conceito de turismo cultural, daí que não nos alongaremos nesse desiderato. Apenas recordamos que o roteiro turístico que propomos se situa no âmbito da sugestão do tipo de turismo cultural advogado por Craick (2003, como citado em Marujo, 2015; ver Tabela 1).

Importa, a partir de agora, mostrar as circunstâncias do país, no qual pretendemos que esse tipo de turismo seja fomentado.

Do ponto de vista geográfico, Moçambique tem 11 províncias, nomeadamente: Maputo Cidade, Maputo Província, Gaza, Inhambane, Sofala, Manica, Tete, Nampula, Zambézia, Cabo Delgado e Niassa.

Falar deste país, do ponto de vista cultural, implica sempre ter em linha de conta a sua dimensão multicultural e multilingue, daí que traçar um roteiro cultural, através da literatura ou em contexto real, implique ter que se cruzar uma multiplicidade de saberes, sob o risco de nunca se ter uma cartografia completa dos seus roteiros culturais e linguísticos. Ainda assim, existe sempre a possibilidade de se estabelecer algumas balizas, como, por exemplo, a indicação da existência de, pelo menos, 11 grupos étnicos, considerando os dados mais recentes advogados por Nhapulo (2010), que fala na existência dos grupos bitonga, tsonga e shopi, nguni, tsonga, complexo zambeze, shona, maconde, macua-lomwé, yao, marave e swahili. Estes dados são diferentes dos apresentados por Rita-Fereira (1976, como citado em Lopes, 2013), que apresenta os seguintes grupos éticos: chopi, ngoni, tsonga, povos do baixo zambeze, shona-karanga, makonde, macua-lomue, yao, marave e muçulmanos da costa litoral norte. Este último não é mencionado por Nhapulo (2010). No atlas de 1960, citado em Jairoce (2012), vêm mencionados os seguintes grupos: thonga-shangane, chopibitonga, nguni-swazi, complexo zambezi (povos cruzados, karanga-shona, ma-konde, macua-lomué, nhanja-yao e maravi) ${ }^{1}$.

Naquilo que concerne às línguas moçambicanas é de se destacar os dados mencionados por Nhampoca (2015), que faz referência à existência de 40 línguas moçambicanas; deste grupo, algumas são línguas e outros são dialectos. A autora não faz a distinção dessas línguas, nem das suas variações e no mesmo texto apresenta como recurso válido a classificação da Ngunga (2004) que advoga a existência das seguintes línguas moçambicanas: kiswahili, kimwani, shimakonde, ciyao, emakwa, ekoti, elomwe, echuabo, cinyanja, cisenga, cisena, cinyungwe, cishona, xitswa, xitsonga, gitonga, cicopi, xironga, swazi e zulu.

Para além dessas línguas e grupos étnicos, importa destacar, por ser importante para o fomento do turismo cultural, um levantamento que consta de Silva $(2010)^{2}$, que nos traz alguns exemplos de danças, nomeadamente: mapiko, lingundumbwe, tahura, tamadune; tufo, maulide, damba; n'sope; masseve; nhau; caluto; utsi, mandowa, madhokodo,

$\overline{1 \text { A grafia depende }}$ de cada fonte consultada.

2 Retirado de http://mozambique-tradicional.com/Mo\%25C3\%25A7ambique--tradicional.php 
makwaia, mukapa, gundula, cikurise, djagadja, mapadza; makwai; makharra, gibhavane, zorre; chigubo, marrabenta. E ainda um conjunto de instrumentos musicais que traduzem ritmos musicais dos moçambicanos, a saber: timbila, xitende; valimba, tambores de muxungwe; chiizambi, phiane, chigovia, tambor; enipiti/xiquitsi; mbiraou xitata ou kalimba; txakari; cacanari. Estes são alguns dos exemplos que convinha pesquisar e saber se foram exaltados pela nossa literatura e se podem ser sugeridos aos turistas.

Existe um outro conjunto de manifestações artísticas moçambicanas não abordadas nesta pesquisa ainda em construção. Entretanto, a partir de um conjunto de obras literárias moçambicanas que fomos lendo aleatoriamente, encontrámos alguns elementos que nos podem alicerçar neste início de um desenho de cartografias literárias que podem contribuir para o fomento do turismo. Neste estudo, iremos, numa primeira parte, mencionar lugares e sítios cantados pela literatura e, numa segunda parte, abordar uma miscelânea de manifestações culturais que podem ser encontradas em diversas obras literárias.

\section{Turismo Cultural em Moçambique: Vertente de Lugares}

A literatura moçambicana é sistematicamente atravessada por várias correntes e linhas. Mas entre elas há uma marca instigante, que nos oferece o seu corpus numa atmosfera de diálogo entre as vozes que a corporizam. Se nalguns casos esse diálogo flui nas costas do Índico, noutros decorre do seu hinterland. Nele encontramos os autores em demanda, numa busca que traz a ressonância dos lugares, os cheiros das suas gentes, dentro de uma cartografia que emana as particularidades de cada lugar. Neste contexto, comecemos pelo extremo sul do país, repassando pelas páginas de O Olho de Hertzog (2010), de João Paulo Borges Coelho. Nesta obra, a estória de Hans Mahrenholz, oficial do exército alemão que chega a Lourenço Marques, no ano de 1919, em busca de rastilho de um mulato, com ascendência grega, fruto de mestiçagem, que decorre da encruzilhada entre povos, que vão deixando marcas. Coelho (2010) insinua-se, pois, o seu desafio é ressuscitar lugares e nomes de referência de Lourenço Marques, "de outro tempo que terá de convocar" (p. 15).

O livro virá a ser assim um roteiro, que nos leva a deleitar-nos com um mercado municipal, $O$ Africano, $O$ Brado Africano (a par da figura pitoresca e de referência, o João Albasini, o seu percursor). Uma narrativa densa, ainda assim instigante, que recupera marcas do Grémio Africano, da praia da Polana, do navio fundeado no porto local. Confrontando o Índico. Coelho (2010, p. 14) faz o inventário de navios, que iluminam a outros lugares: Niassa, Beira.

O Olho de Hertzog virá a ser, por isso, um itinerário a pé (Coelho, 2010, p. 24), pela história de Moçambique, transcendido destes lugares nostálgicos, de um passado saudoso, que rastreia o presente, de um passado que interpela e interfere na actualidade, demonstrando-se que os alicerces de uma nação estão nas marcas seculares que revisita, funcionando esta obra como um cartão-de-visita, que nos faz reconhecer a tabuleta Wenela (Coelho, 2010, p. 82), mostrando-nos aventuras e curiosidades de conhecer a vizinha África do Sul, com os seus compounds, onde confluem gentes de Moçambique. 
A obra procura reconstituir o passado, numa teia que ressuscita esses lugares pictóricos e emblemáticos transvertidos pela miragem e que ainda assim nos engancham, pela vitalidade que se nos oferece, descrevendo personagens femininas exóticas, que nos ampliam a vontade de seguir esse olho emprestado, suscitado pelo desembarque no Niassa, de contingentes militares alemães, aquando da Segunda Guerra Mundial, num rastilho até ao fim.

O Olho de Hertzog sugere-nos ser, por isso, o olho de Coelho (2010) em diálogo com a sua escrita e que tende a iludir-nos, levando-nos para Machangulo (p. 51), a Salamanga, a Bela Vista, Ponta Malongane (p. 62), a Ponta Torres, do outro lado do esteiro (p. 104), ou à suave encosta de Zitundo, lá "onde os albatrozes fazem ninhos nas torres de metal enferrujado" (p. 83), ao outro extremo da actual província de Maputo, palco de "aterrorizadores batuques e macabras cerimónias" (p. 94), onde os olhos arregalados de Coelho arregram-se, à rebeldia dos pés descalços do velho Josefate Ngwetana e às galinhas, pilões, esteiras, aos nhamessoros com uma fronte que brilha, "contudo, de astúcia" (p. 98). Neste olhar que assume a errância e enraizamento, damo-nos conta de que nos afastamos "um pouco para sentir a terra, invadido pela volúpia de olhar os lugares e poder nomeá-los” (Coelho, 2010, p. 107). Não se trata de um olhar indiferente, mas de entrosamento, tal como o faz na Inhaca:

por qualquer Razão desconhecida nunca se preocupou Deus em entender a sua sombra protectora à nossa Itha da Inhaca, espalhando nela os seus templos. Talvez por isso haja aqui muito sol e pouca sombra nos meses do fim do ano, muita malária. (Coelho, 2010, p. 11)

Coelho persegue uma herança já cimentada, por vozes perturbadoras e prazerosas da literatura moçambicana, como o Calane da Silva em Dos Meninos da Malanga (1982) e em Xixandarinha na Lenha do Mundo (1987); ou um dos seus mais profícuos percursores: Virgílio de Lemos, que no livro Negra Azul revisita Lourenço Marques e afirma:

"Viagem pela rua dos casinos"

(ao Fernando Ferreira / ao Reinaldo F.)

A velha rua dos casinos ri-se

velha cigana, tempo

que vai a rua para dar

um ar da sua graça:

na noite, guerras de sedução,

passeiam-se velhas e jovens

putas, marinheiros, músicos,

mangas de alpaca.

Corpos que se exibem, sexos

que ejaculam,

do solitário deserto

ao imprevisível vulcão.

(Lemos, como citado em “[0421] Virgílio de Lemos, a Rotura Com o Colonialismo", 2018) 
Sobre os lugares, Coelho tem muito a dizer. E insiste-o nas obras $A$ Cidade dos Espelhos (2011); Ponta Gêa (2017); As Duas Sombras do Rio (2003), numa demanda em que ele se permite, como Mia Couto em Terra Sonâmbula (1992) e Nelson Saúte em Narradores da Sobrevivência (2000), deixar a cidade do Maputo, cruzar a fronteira da guerra, até ao rio Zambeze (pela N1, a estrada - há pouco povoada de machibombos calcinados e em torresmos). Depois deste trânsito e uma paragem pela Beira, será nas orlas do Rio dos Bons Sinais (2008), recuperado por Saúte, em Quelimane, na Zambézia dos palmares, das senhoras donas dos prazos, na Zambézia do chazeiros e sisais, a Zambézia do Naparama Kindzu, que os três escribas se reencontram num diálogo pervertido sobre a terra despojada pela guerra civil. Naquela "estrada morta" é recuperada a memória e a vitalidade.

Paulina Chiziane junta-se-lhes. Lança a âncora, fixando-se nos cenários coloniais, ainda hoje muito presentes, que muito recordam a obra de Emílio de San Bruno, em Zambeziana: Cenas da Vida Colonial (Bruno, 1999).

Os navegadores correram de aldeia a aldeia, derramando sangue, profanando túmulos, pervertendo a história, fazendo o impensável. A Zambézia abriu seu corpo de mulher e se engravidou de espinhos e fel... Foi assim que começou a história de José muitos séculos do seu nascimento. (Chiziane, 2010, p. 69)

Neste olhar de afeto, Coelho desdobra-se num entrecruzamento com as vozes que o antecedem, na sua transposição a Catembe e Xefina. Curiosamente, uma Xefina já dissecada e glosada pelo prolixo escritor Juvenal Bucuane, em Xefina e Zevo (1989/2009). Bucuane recupera a ilha, uma ilha-terra, ilha-prisão, chão de protesto e revolta, de amores e desamores, é um lugar dimanado por Bucuane, que a procura aludir.

É verdade que os etno-espaços não são lineares nem compartimentos estanques. Há um fluir num princípio de vasos comunicantes, por isso, com Mulheres de Cinza (Couto, 2015) e em "O Bebedor do Tempo" do Livro Estórias Abensonhadas (2003), de Mia Couto, mapeámos o Mussorize, em Manica, Manjacaze, em Gaza e encontramos o húmus do seu chão fértil de rebeldias. A viagem/leitura leva-nos ao Limpopo, e nisto, passando por Inhambane, narrada por Elton Rebello, no seu livro Nyandayeyo (1990), descrevendo Govuro, concretamente Mambone. Lembrando ainda em Balada de Amor ao Vento (2004), de Paulina Chiziane, que fala sobre Sarnau e Mwando, que protagonizam uma estória de amor, fazendo corpo com a fome e a guerra civil, com o desafio do feminismo no século XX, livros de imagens pungentes e dolorosas, que omitem o panorama paisagístico, para dar corpo à revolta, à fome, a substâncias a que se recorre para se suportar o sofrimento.

Rebello, um dos ativistas culturais da Beira dos finais da década de 1980, através da página "Diálogo", do Diário de Moçambique, que é contemporâneo de Bahassane Adamodjy, conta a história da cidade da Beira, nas páginas dos seus livros Mussodjy (1993), no qual Xipangara é uma presença indelével e em Milandos de um Sonho (2001), evocando o Mussiquite, zona do Matacuane, bairro que se situa junto ao quartel do Matacuane, onde as tropas coloniais desfrutavam da consolação de mulheres negras com as quais multiplicaram a espécie, o que originou uma grande 
mestiçagem. Esse itinerário poderá prosseguir para Quiteve, nas margens do Rio Púnguè, onde se poderá assistir aos mais insignes rituais do deus Zuze, através da obra Contos e Lendas de Carneiro Gonçalves (1981), contraponto da sereia, que ilude os seus apaixonados, levando-os ao precipício.

Outros escritores e poetas oferecem-nos um manancial de referências cartográficas e geográficas deste país, sustentáculo de tecidos pélvicos diferentes, de especiarias do oriente. Território de ilhas, objetos-sujeitos de evocação de poetas, como de prosadores. Não conhecemos nenhuma ilha que não tenha sido cantada, homenageada por escribas. Tratando do mar como o mais antigo meio que coloca os povos em contacto, alguns dimanaram o Atlântico, o Mediterrâneo, atravessaram as tormentas do Cabo das Agulhas. Entre nós, a ilha que mais apaixonou almas e fecundou escritos no céu útero é a Itha de Moçambique. Lília Momplé, em Ninguém Matou Suhura (1988), oferece-nos uma descrição assombrosa sobre ela, especialmente sobre o Litine, o Esteu e a Marangonha, apanham a contra-costa e, em pouco tempo, estão na praia.

A llha de Moçambique é deveras assediada, seduzida por um séquito de poetas que a amaram. Nenhum deles amou mais do que o outro o seu chão, por isso, o amor da ilha aos poetas reparte-se por frações iguais. Mesmo que não desejemos repetir o que dela tenha sido evocado, há sinais, signos, que nos devolvem a Muípite, berço da nação. Oprimida pelas águas que a cercam como uma misteriosa muralha, a Itha de Moçambique ao longo dos anos vai seduzindo poetas, desde Luís de Camões e Tomás António Gonzaga que nela viveram, até Jorge de Sena, Alberto de Lacerda, Rui Knopfli, Luís Filipe Castro Mendes, Alexandre Lobato, Luís Carlos Patraquim, Eduardo Pita, Eduardo White, Virgílio de Lemos, Nelson Saúte, Adelino Timóteo e Sangare Okapi, que redimensionaram o seu espaço e cartografaram a sua geografia, num encanto que a sobreleva, apesar de claros sinais de decadência que a enfermam.

Os poetas pertencem à humanidade e, por isso, são parte integrante do património da ilha. Nenhuma ilha é tão rica para recusar o galanteio, os cânticos dos donos da insularidade que a reinventariam. A "ilha de coral" não só seduziu os pangaios e as caravelas que a assediaram no século XV como também vem repetindo os seus galanteios a aventureiros, estranhos e pessoas comuns, que nela encontram a sua morada de acolhimento.

Um outro poeta que cantou a ilha e que não pode deixar de ser mencionado é Luís Carlos Patraquim, que na sua obra Vinte e Tal Novas Formulações e uma Elegia Carnívora (1991) exalta esta ilha (Muípite) e a sua cidade de pedra e cal; o seu mais cantado produto de beleza, m'siro; a dança n'sope e o cartão de visitas, o minarete.

A ilha é um misto de osmose macua, swahili, árabe e português, línguas que lá se falam. Virgílio de Lemos traduz este misticismo em versos, falando das mulheres crioulas da ilha, das makuas, kimoenes e do seu m'siro. A ilha é para a plêiade de poetas que lhe revisitam o corpo, o fermento da sua identidade. É, praticamente um símbolo de viagem de migração. 0 tal barco, como diria Sangare Okapi, na sua obra Mesmos Barcos ou Poemas de Revisitação do Corpo (2007). 
Sinónimo de cumplicidade e afeto, como nos sugere Eduardo White, poeta do amor, na sua obra Homoíne (White, 1987):

amo-te sem recusas e o meu amor é esta fortaleza, esta Ilha encantada, estas memórias sobre as paredes e ninguém sabe deste pangaio que a Norte e na Ilha traz um amante inconformado. Em tudo habita ainda a tua imagem, o m'siro purificado da tua beleza e das tuas sedes. (p. 12)

A ilha seduzida é por isso a maresia, o fluido libertado pelos corpos ofegantes, na linguagem corporal e turística, pois quem a visita pode sentir esse misto de cumplicidade entre terra/homem/mulher, fundidos numa só palavra. Numa só utopia. Outros autores exaltaram a ilha, a saber: Rui Knopfli, no seu livro Iha do Próspero (1972); Orlando Mendes, no seu poema "Minha Itha":

por ali estiveram Camões das amarguras itinerantes

e Gonzaga da Inconfidência no desterro em lado oposto.

Era a rota dos gemidos e das raivas putrefactas

e dos partos que haviam de povoar as Américas

com braços marcados a ferro nas lavras e colheitas. (Mendes, como citado em Saúte \& Sopa, 1992, p. 39)

A ilha não é só o lugar de fundação da nação literária moçambicana, mas ponto de partida para outros voos. Ela suscita a história, as histórias, as memórias e cumplicidades difíceis de lembrar, como Nelson Saúte no poema "A Itha dos Poetas" faz questão de evocar.

Depois de Nampula, podemos dar a conhecer Cuamba, província de Niassa, num trajecto com $O$ Comboio de Sal e Açúcar, obra cinematográfica de Licínio de Azevedo (1997), também publicada em livro. Em Niassa podem presenciar-se as mazelas de um tempo roubado até às vísceras representadas em No Reino dos Abutres (2002), de Ungulani Ba Ka Khosa e ainda através da sua obra Entre as Memórias Silenciadas (2013), que nos fala sobre os sertões dos campos de concentração.

E para evadirmos desse pungente desencanto que tolhe a alma de qualquer um, sugerimos uma travessia para Cabo Delgado, de onde, pela mão de Glória de Sant'Ana, por Pemba e pela Itha de Ibo, com certeza, terra cantada pelo poeta autóctone Júlio Carrilho, através do livro Dentro de Mim Outra Ilha (1993).

Fica assim, ainda que de modo inacabado, traçado um roteiro para, através de leituras, promover o turismo cultural em Moçambique.

\section{Turismo Cultural em Moçambique: Vertente de Culturas}

Este segundo momento do texto recupera grande parte da informação já estudada em Laisse (2019), em referência à necessidade de se estabelecer, em Moçambique, um cânone multicultural. Esse mesmo e com as representações simbólicas que 
contém, especialmente no que à cultura diz respeito, pode ser utilizado como recurso para estimular o turismo cultural. Assim, segue-se uma lista de representações culturais passíveis de serem encontradas em Moçambique.

O lobolo é uma tradição cultural do sul de Moçambique que consiste na entrega de um dote por parte da família do noivo à família da sua noiva. Tem acontecido, de um modo geral, nas etnias tsonga, nguni, bitonga e chope. As suas representações culturais podem ser lidas em alguns dos textos que passaremos a mencionar: As Mortes de Lucas Mateus (Cenas I a VI) de Leite de Vasconcelos; Ser Mulher de Sant'Ana Afonso; Niketche (2002) de Paulina Chiziane e Sia-Vuma de José Craveirinha.

Na última obra referida, podemos ainda encontrar a exaltação de danças tradicionais da etnia tsonga como o xigubo, xingomanas, marrabenta e dos xipendanas, para além do som das timbilas, instrumento eleito para Património Cultural da Humanidade, em 2005. As marimbas, artefactos ligados a esse património, são cantadas no "Poema para Eurídice Negra" de Sérgio Vieira (1983), em Também Memória do Povo. Estas danças e instrumentos ensinam ou sugerem as tradições dos grupos étnicos tsonga e chope.

Na obra Niketche (2002), nome de uma dança, Paulina Chiziane aborda também a poliandria, tradição dos macua lomwé e ainda a poligamia, tradição praticada pelas sociedades patrilineares africanas. Lília Momplé, em Os Olhos da Cobra Verde (1997) faz referências à pele aveludada, resultante da utilização de m'siro. Esta tradição, mais a de esticar os lábios vaginais, bezuntando-os com ervas (durante a puberdade, no âmbito dos ritos de iniciação), é realizada pelo grupos étnicos macua-lomwé e makonde.

O pau preto, uma relíquia makonde é exaltado no poema "Se me Quiseres Conhecer" da autoria de Noémia de Sousa (2001). Para além da sua beleza artística, a madeira que dá nome ao pau tem valor turístico e económico. Ainda relativamente a este grupo étnico, Felizmina Velho, através de Chilendela Maconde Foi Riscada do Mapa (2001), sugere-nos a aprendizagem sobre tradições ligadas à morte, como o caso de não se dever chorar nos funerais. Ela exalta ainda as tatuagens makonde e a dança do mapiko.

O canhu, uma bebida tradicional do sul de Moçambique é celebrado na Orgia dos Loucos (1990) de Ungulani Ba Ka Khosa, autor que em Ualalapi (1987) faz referência a outras bebidas tradicionais típicas para os shonas e para o grupo étnico complexo zambeze, nomeadamente: pombe e doro.

Uma das tradições dos nguni, que é a interdição de consumir peixe é também tratada nessa obra. Este autor, Ungulani Ba Ka Khosa, em Choriro (2009), também em referência ao complexo zambeze ao ensinar-nos sobre o ritual do mesmo nome, que designa o caos, choro, lamento, luto, uma prática social vivida nesse lugar. Outros símbolos representados no livro são chuanga e chicuacha, gugudas/gogodelas, gugudas ou gogodelas, espingardas de fabrico caseiro, que são artefactos tradicionais dos povos do complexo zambeze. 
Em Nónumar (2001), Júlio Carrilho, através de referência a expressões mwani, língua intelegível ao swahili, dá-nos a conhecer o lussúngo, pano fino de algodão que as mulheres usam para cobrir a cabeça e o tronco e os mwani, nome utilizado para designar os praeiro naquela região do litoral de Moçambique, a província de Cabo Delgado. Ainda relativamente a essa província, podemos encontrar em Xigubo (1995), de José Craveirinha uma alusão a este grupo étnico, que fala a língua do mesmo nome.

Graça Torres, em Niassa, Terra de Mel...e Leite Amargos (2005), fala-nos do ajaua, terra habitada pelo povo yao. Para além de outros símbolos, nesta obra podemos encontrar o cindona-ndona, um tipo de jogo praticado por aquele povo, o que nos pode permitir obter algum conhecimento de parte deste grupo étnico. Esta autora, na mesma obra, sugere-nos ainda o conhecimento do cuende, um tambor e do nhau, património cultural e imaterial da humanidade, uma dança do povo marave.

Ficam assim mencionadas algumas representações culturais dos povos de Moçambique, a partir da referência aos grupos étnicos. Certamente que muitas outras obras sugerirão outras representações culturais e promoveriam o turismo cultural, entretanto, elencámos as mencionadas, a maior parte das quais faz parte de um conjunto de obras publicadas entre 2000 e 2011, no país.

\section{Considerações Finais}

Através deste estudo descritivo-exploratório, elencámos um conjunto de obras que contêm representação de espaços e de culturas que sugerem lugares para visitar em Moçambique.

Ao defendermos que o roteiro proposto possa contribuir para alavancar o turismo cultural, fazemo-lo recorrendo à ideia de que uma das funções da literatura é a de mimetizar a sociedade e, consequentemente sugerir a existência do objecto representado.

Assim, comprando e lendo as obras literárias mencionadas e outras, certamente, porque existem, o leitor poderá sofrer influência desses textos e sentir-se estimulado a conhecê-los e a fazer o reconhecimento dos lugares e culturas lidos. Isso estimula o desenvolvimento humano, intelectual e turístico, se bem geridos.

\section{Referências}

Adamodjy, B. (1993) Mussodjy. Diário de Moçambique.

Adamodjy, B. (2001). Milandos de um sonho. Quetzal Editores.

Azevedo, L. (1997). Comboio de sal e açúcar. Ndjira.

Bruno, E. de S. (1999). Zambeziana: Cenas da vida colonial. Arquivo Histórico de Moçambique.

Bucuane, J. (2009). Xefina e Zevo. Cadernos Tempo. (Trabalho original publicado em 1989)

Carrilho, J. (1993). Dentro de mim outra ilha. AEMO

Carrilho, J. (2001). Nónumar. Ndjira. 
Chiziane, P. (2002). Niketche. Uma história de poligamia. Ndjira.

Chiziane, P. (2004). Balada de amor ao vento. Caminho.

Chiziane, P. (2010). O alegre canto da perdiz. Ndjira.

Coelho, J. P. B. (2003). As duas sombras do rio. Caminho.

Coelho, J. P. B. (2010). O olho de Hertzog. Leya.

Coelho, J. P. B. (2011). A cidade dos espelhos. Caminho.

Coelho, J. P. B. (2017). Ponta Gêa. Caminho.

Couto, M. (1992). Terra sonâmbula. Caminho.

Couto, M. (2003). Estórias abensonhadas. Caminho.

Couto, M. (2015). Mulheres de cinza. Caminho.

Craveirinha, J. (1995). Xigubo. AEMO.

Culler, J. (1997). Literature and cultural studies. In J. Culler (Ed.), Literary theory: A very short introduction (pp. 42-54). Oxford University Press.

Gonçalves, C. (1981). Contos e lendas. Edições 70.

Horellou-Lafarge, C., \& Segré, M. (2010). Sociologia da leitura (M. Gama, Trad.). Ateliê Editorial. (Trabalho original publicado em 2003)

Iser, W. (2001). A ficcionalização como dimensão antropológica da literatura. In H. Buescu, J. F. Duarte, \& M. Gusmão (Eds.), Floresta encantada: Novos caminhos da literatura comparada (pp. 101-120). Dom Quixote.

Jairoce, J. (2012, 17 de setembro). Grupos étnicos de moçambique. Blog Historiando: Debates e Ideias. http://jorgejairoce.blogspot.pt/2012/09/grupos-etnicos-de-mocambique.html

Jauss, H. (1993). A literatura como provocação: História da literatura como provocação literária (T. Cruz, Trad.). Vega.

Khosa, U. B. K. (1987). Ualalapi. AEMO.

Khosa, U. B. K. (1990). Orgia dos loucos. AEMO.

Khosa, U. B. K. (2002). No reino dos abutres. Imprensa Universitária.

Khosa, U. B. K. (2009). Choriro. Alcance.

Khosa, U. B. K. (2013). Entre as memórias silenciadas. Alcance.

Knopfli, R. (1972). Ilha do próspero. Minerva Central.

Laisse, S. (2015). Moçambique, Surge et Ambula: A interculturalidade no corpus literário obrigatório no ensino secundário geral entre 2004 e 2011 [Dissertação de doutoramento, Universidade Nova de Lisboa]. Repositório Universidade Nova. http://hdl.handle.net/10362/16237

Laisse, S. (2019). Cânone e a interculturalidade no corpus literário obrigatório no ensino secundário geral em Moçambique. In A. Leite, S. Laisse, \& V. Pinheiro (Eds.), Seis reflexões em torno do cânone literário moçambicano (pp. 11-39). Alcance.

Lopes, J. (2013). Cultura acústica e letramento em Moçambique: Em busca de fundamentos antropológicos para uma educação intercultural. Educ.

Marujo, N. (2015). $O$ estudo académico do turismo cultural. Revista TURyDES: Turismo y Desarrollo Local, 8(18). http://www.eumed.net/rev/turydes/18/turismo-cultural.html 
Momplé, L. (1988). Ninguém matou Suhura. AEMO.

Momplé, L. (1997). Os olhos da cobra verde. Associação dos Escritores Moçambicanos.

Ngunga, A. (2004). Introdução à linguística bantu. Imprensa Universitária.

Nhampoca, E. C. (2015). Ensino bilingue em Moçambique: Introdução e percursos. Working Papers em Linguística, 16(2), 82-100. https://doi.org/10.5007/1984-8420.2015v16n2p82

Nhapulo, T. (2010). Atlas histórico de Moçambique. Plural Editores.

Okapi, S. (2007). Mesmos barcos ou poemas de revisitação do corpo. AEMO

Patraquim, L. (1991). Vinte e tal novas formulações e uma elegia carnívora. Edições ALAC.

Rebello, E. (1990). Nyandayeyo. AEMO

Saúte, N. (2000). Narradores da sobrevivência. Dom Quixote.

Saúte, N. (2008). Rio dos bons sinais. Dom Quixote.

Saúte, N., \& Sopa, A. (1992). A llha de Moçambique na voz dos poetas. Edições 70.

Silva, C. (1982). Dos meninos da Malanga. Cadernos Tempo.

Silva, C. (1987). Xixandarinha na lenha do mundo. AEMO.

Sousa, N. de. (2001). Sangue negro. AEMO.

Torres, G. (2005). Niassa, terra de mel...e leite amargos. CEDIMA; Edição da autora.

Velho, F. (2001). Chilendela maconde foi riscada do mapa. Ndjira.

Vieira, S. (1983). Também memória do povo. Associação dos Escritores Moçambicanos.

White, E (1987). Homoíne. AEMO.

[0421] Virgílio de Lemos, a rotura com o colonialismo. (2018, 17 de novembro). Ibn Mucana. http://ibnmucanapoesia.blogspot.com/2018/11/0421-virgilio-de-lemos-rotura-com-o.html 